\title{
Investigating Student's Acceptance of an EDMODO Content Management System
}

\section{Farah Mohamad Zain}

Universiti Utara Malaysia, Malaysia,mz.farah@uum.edu.my

\section{Effariza Hanafi}

Universiti Malaya, Malaysia

\section{Yahya Don}

Universiti Utara Malaysia, Malaysia,d.yahya@uum.edu.my

\section{Mohd Faiz Mohd Yaakob}

Universiti Utara Malaysia, Malaysia,mohd.faiz@uum.edu.my

\section{Siti Nazuar Sailin}

Universiti Utara Malaysia, Malaysia, sitinaz@uum.edu.my

The aim of this study is to examine the factors that influenced the use of Edmodo content management system to support the teaching and learning in a flipped classroom context. Using an extended technology acceptance model (TAM), we adopted a revised model consisting of two external factors (Content Quality and Motivation) that may influence students' perceptions and acceptance of the system. A total of 42 students were involved in this study. The students attended a course in a flipped classroom environment. The findings of the study utilizing the multiple regression analysis revealed that the Edmodo content management system was well accepted where the Content Quality acted as a good external factor and able to predict the students Perception of Usefulness and Perception Ease of Use. As for Motivation, it was found that there was no positive relationship with the Perception of Usefulness.

Keywords: Edmodo, technology acceptance model, flipped classroom, teaching, learning

\section{INTRODUCTION}

Edmodo content management system (ECMS) is one of the Web 2.0 tools and also a web-based social networking application that is ideal to be integrated as a learning platform. ECMS is also listed in 'Top 200 Tools for Education 2018' and is on 185

Citation: Zain, F. M., Hanafi, E., Don, Y., Yaakob, M. F. M., \& Sailin, S. N. (2019). Investigating Student's Acceptance of an EDMODO Content Management System. International Journal of Instruction, 12(4), 1-16. https://doi.org/10.29333/iji.2019.1241a 
ranked (www.toptools4learning.com). The ECMS has the appropriate educational features as a teaching medium for all levels of education and training. It is free to use and lecturers have full control to connect with other lecturers and students (Kongchan, 2013). In addition, ECMS provides a safe environment as a learning resource, assessment and communication tool.

One of the key features of ECMS is forum board for collaborating students to help clarify issues related to learning materials and activities (Bruce, 2013). In addition, forum boards also allow members to view other members' contributions to the activities carried out and provide immediate response, thus creating interactions, generating collaborative and interactive learning environments (Healey \& Bryan-Kinns, 2000). Through this platform, the teachers can share videos, pictures, office files, questionnaires, links and embed codes with their students (Dogan, 2012).

ECMS also works to test students' understanding by providing interactive activities or quizzes throughout the teaching and learning process (Thongmak, 2013). These activities are useful for lecturers to evaluate student's performance. It is also interesting and effective way to evaluate student's performance within the specified time frame. Students get scores as soon as the quiz session ends. In this way, students are able to learn a topic not only through lecture sessions with lecturers but are also trained to refer and analyze each topic more deeply. Learning support through comments or suggestions from colleagues and lecturers is also helping students in the learning process and students are no longer bound or dependent entirely with lecturers in the classroom.

ECMS also promotes teaching and learning using flipped classroom approaches. Flipped classroom is a pedagogical model in which teaching and learning is taken place inside the classroom now take place outside the classroom and vice versa. Short videos are seen in advance by students before a lecture session while in class, lecturer focus on training and discussion (Tucker, 2012). Video lecture either developed by a lecturer or selected from online repositories are often seen as the main ingredient in flipped classroom approaches. This approach encourages active learning, student's engagement, hybrid course design and podcasting courses (Bergmann \& Sams, 2012). The advantage of this method is that lecturers can ask questions about course content, test student skills and interact with each other during hands-on activities. During lecture sessions, the lecturer act as facilitator to encourage students to collaborate.

One of the important aspects when introducing a technology is the extent to which the acceptance and use of these technologies are accepted by the students (Yeou, 2016). Therefore, it is important for researchers to know the background that can explain and predict the success of the use of the technology among students. In a study on the adoption of a technology-based system, the popular model used is Technology Acceptance Model (TAM) proposed by Davis (1989). Perceived usefulness (PU) and perceived ease of use (PEoU) are two powerful determinants of TAM and able to influence attitudes towards use and purpose of use which in turn affects the actual use of the system (Nagy, 2018). In addition to these two key factors, TAM emphasizes that external factors also affect the usefulness and ease of use of the system. 
TAM has been applied in many studies (Hsu \& Chang, 2013; Alharbi \& Drew, 2014; Al-Assaf et al., 2015) and proved to be successful as it demonstrates a unique way of predicting student's behavioural intention (BI) to use a technology-based system. There are various studies that have been conducted to improve the TAM (Lee et al., 2013; Taherdoost et al., 2011; Lee \& Lehto, 2013) by exploring various external factors that can act to influence perceived ease of use (PEoU) and perceived usefulness (PU) in an attempt to increase TAM's early perception.

In this study, efforts have been made to expand the TAM by introducing external factors in terms of Motivation (Mo) and Content Quality (CQ) attributes. As Davis (1989) states, there are various external factors or stimuli that can influence student behavior. It is expected that this effort will enhance the effectiveness of TAM and its relevance to the attributes of PEoU, PU and ultimately BI to use the system.

\section{RESEARCH MODEL AND HYPOTHESES}

The variables included in the research model (Figure 1) are the standard TAM constructs: PEoU, PU, attitude towards use (AtU), BI and actual use (AU), along with external variables, Mo and CQ.

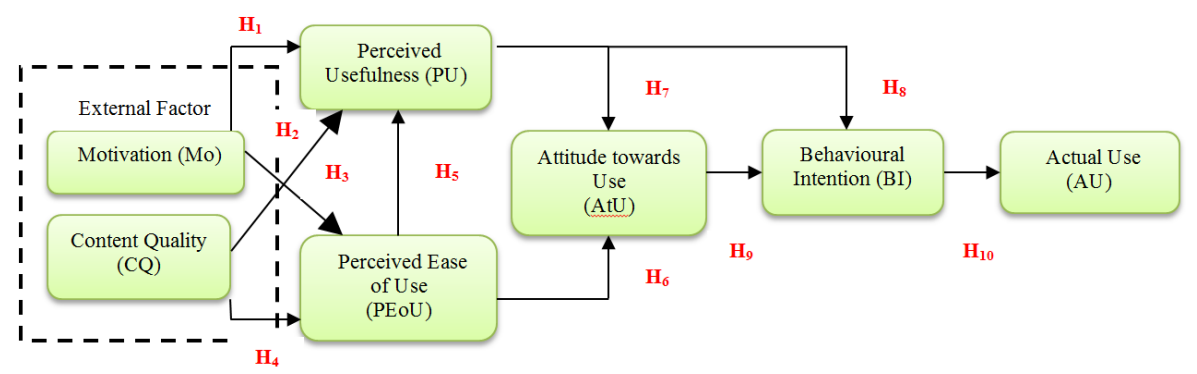

Figure 1

Structural Model and Hypotheses

With its many extensions, the TAM has emerged as a leading scientific model for investigating acceptance and usage of technology by teachers, students and other stakeholders in different contexts (Masa'deh et al., 2015; Abdullah \& Ward, 2016; Esterhuyse \& Scholtz, 2016; Anormaliza et al., 2015). Legris et al., (2003) revealed that there is a necessity to investigate other variables in order to provide a broader view and a better explanation of technology adoption. A number of research studies have extended the model by adding external variables, such as emotional attachment (Teo, 2014), teacher self-efficacy (Teeroovengadum, Heeraman \& Jugurnath, 2017), quality of work life (Tarhini et al., 2014), system quality (Wu \& Zhang, 2014), and information quality (Hediyeh et al., 2013) in order to strengthen the model. Against this backdrop, this study extends the original TAM framework by adding motivation and content quality as an external factor.

\section{Motivation (Mo)}

In learning through social networking sites, users are the key to the successful of the 
learning environment system (Teo, 2014). Therefore, what factors affecting the intention to use a particular system continue to be an important issue. Many studies relate the behavioral intention with the motivation perspective (Lin \& Lu, 2011; Chen \& Tseng, 2012).

Mo is a major factor in determining human behavior and action (Abdul Jalil \& Zainuddin, 2015). It refers to student's feelings of excitement, pleasure and joyful and this plays an important role in explaining the acceptance of users and their behavioral intentions in web-based learning (Lee et al., 2005; Saadé \& Bahli, 2005). When a student engages in activity from the beginning to the end, the student is considered motivated, as opposed to the unmotivated students. Mo is divided into two, namely extrinsic and intrinsic motivation (Deci, 1975). Extrinsic motivation focuses on the cause of motivation, such as rewards or benefits gained when doing an activity while intrinsic motivation exhibits excitement and satisfaction derived from certain activities (Saade, 2007). Both motivation (extrinsic and intrinsic) capable of influencing individual intentions on their actual activity and behavior (Moon \& Kim, 2001).

In this study, the researcher examines the influence of Mo attributes to PU and PEoU. Justification for selecting Mo as an external factor is because Mo plays an important role in influencing the intention to continue using ECMS. An enjoyable student using social networking sites usually has a high motivation (Sik \& Lee, 2010). In this study, high motivation is required in each student to ensure they engage in activities within the ECMS throughout the semester. Students were encouraged to do or repeat an activity that is more fun than doing the same activity but not fun. Therefore, the researcher expects Mo to have a positive relationship with the PU as well as PEoU. Therefore, hypothesis 1 and hypothesis 2 are proposed.

$H_{1}$ : There is positive and direct impact of Mo towards the PU of ECMS.

$\mathrm{H}_{2}$ : There is positive and direct impact of Mo towards the PEoU of ECMS.

\section{Content Quality (CQ)}

According to Haderi (2014), CQ covers the content richness and update regularity. Content richness is defined as rich in learning resources where students have the access to enrich their learning activities (Young \& Lehto, 2013) while the constantly updated content shows that content quality can be improved (Lee, 2006). The design of online learning content should be the same as the format in the classroom in terms of course description, objectives, learning content, goals, scope and assessment (Barker, 1994).

Some studies show that higher perceptions of the CQ, the higher usefulness of the system (Lee, 2006; Park et al., 2012). Jung et al. (2009) found that content has a direct relationship with the perception of mobile TV usefulness. This is supported by Lee at al., (2014) and Udo et al., (2010) study that CQ is a powerful predictor for PU and PEoU.

ECMS has greater appeal to students as the richness of content derived from the Internet compared to traditional learning methods. Students, lecturers and peers can find relevant content on the Internet and then share on ECMS forum boards. If a student using ECMS 
as a learning medium finds the CQ is high, it is likely that the student has a positive impact on learning and will use ECMS. Therefore, it is reasonable to assume that the CQ on ECMS has a positive relationship with the acceptance of the student to ECMS.

Additionally, content in ECMS can be updated anytime and anywhere. Chen et al. (2003) found that student satisfaction will increase significantly if they can get updated e-learning content on a regular basis. Updating content and new content will bring students to feel that ECMS is useful and meaningful to gain new knowledge and learning. Therefore, researchers choose CQ as an external factor in extended TAM.

In this study, researchers stress CQ to be presented through texts, multimedia presentations, videos and power point presentations. This CQ is expected to have a positive relationship with PU and PEoU. Therefore, hypothesis 3 and hypothesis 4 are proposed.

H3: There is positive and direct impact of CQ towards the PU of ECMS.

H4: There is positive and direct impact of CQ towards the PEoU of ECMS.

\section{Perceived Ease of Use (PEoU)}

The PEoU are defined as the extent to which the technology is free of effort when it is used (Moore \& Benbasat, 1991). In this study, the PEoU of ECMS is defined as the degree to which the user believes that using ECMS will be effortless. The PEoU in using technology are influenced by several factors. Among them is the technology itself as a student experience of similar technologies. The second factor is the reputation of the technology. Good reputation will convince students about the use of the technology. The third factor is the existence of a support mechanism. This support mechanism is necessary if students are having trouble using technology.

The findings show that technological acceptance increases as the PEoU increases (Mohamed, 2016; Huang, 2017). PEoU is seen to increase AtU (Cheung \& Vogel, 2013; Calisir et al., 2015), PU (Wu et al., 2013), BI (Chen \& Tseng, 2012; Wu et al., 2013), intrinsic motivation (Tan, 2010) and perception of excitement (Cheng, 2012). However, there are also some differences in the findings. For example, Shyu and Huang (2011) states that there is no PEoU effect on AtU.

There are several factors that influence the PEoU in a study that focuses on online learning including compatibility (Cheung \& Vogel, 2013), resource (Cheung \& Vogel, 2013), motivation to use (Chen \& Tseng, 2012; Wu, et al., 2013), student-system interaction (Cheng, 2013), student-instructional interaction (Cheng, 2013), student interaction (Cheng, 2013), quality of information (Cheng, 2012), quality of service (Cheng, 2012) and system quality (Calisir et al., 2015).

This study selects the PEoU attributes to see how far ECMS's student use and the influence of PEoU on PU. Researchers expect PEoU will influence PU and students will continue to use ECMS in the future. Hence the hypothesis 5 and the hypothesis 7 are proposed. 
$H_{5}$ : There is positive and direct impact of PEoU towards the PU of ECMS.

$H_{6}$ : There is positive and direct impact of PEoU towards the AtU of ECMS.

\section{Perceived Usefulness (PU)}

PU is defined as the degree to which a user believes that a particular system will enhance his/her performance (Davis, 1986). In this study, the PU of ECMS is defined as the degree to which the user believes that using ECMS would boost his or her learning performance. From a theoretical perspective, TAM suggests that when a person intends to act, the PU is the predecessor of a person's BI before they actually act. Literature review in different academic fields (Yucel, 2013; Taylor et al., 2014; Wu et al., 2013; Tarhini et al., 2014; Tarhini et al., 2013; Purnomo \& Lee, 2013) have highlighted the importance of PU in the adoption of new technologies. Consumers who believe in PU relationships will lead to technology acceptance (Davis, 1989) and consequently influence the BI to use technology (Lin et al., 2014). Young \& Lehto (2013) in "YouTube acceptance for learning procedures: Advanced Technology Acceptance Model", concludes that PU acts directly in the way that it affects the user's acceptance.

Lai et al., (2012) argue that pedagogical encouragement and advice from teachers and colleagues may help students to realize the usefulness of a technology for learning while increasing the acceptance of technology. When students feel that the use of technology is appropriate to the needs and style of learning and is compatible with their beliefs about learning, they are more likely to assume that technology is very useful for learning and enhances more positive attitude towards technology (Lai et al., 2012). At the same time, PU from the point of view of educators (i.e., greater control over work, improving work performance, saving time, accomplishing tasks faster and improving effectiveness) can influence their BI to adopt the e-Learning system.

This study chooses PU attributes to see how far ECMS uses to students and PU's influence on AtU and BI. Researchers expect PU to influence student AtT and student intentions to continue using ECMS in the future. Therefore, the hypothesis 7 and the hypothesis 8 are proposed.

H7: There is positive and direct impact of PU towards the AtU of ECMS.

H8: There is positive and direct impact of PU towards the BI of ECMS.

\section{Attitude towards Use (AtU)}

AtU is acceptance or rejection when a person uses technology in his / her work. Researchers also argue that attitude affects individual behavior. This attitude consists of cognitive, affective and behavioural components.

Many studies have examined AtU on technology acceptance and the findings show that AtU can increase BI (Calisir et al., 2015; Shyu \& Huang, 2011). There are two factors that affect AtU in studies focusing on online learning that is PEoU (Calisir et al., 2015; Taylor et al., 2014) and PU (Calisir et al., 2015; Taylor et al., 2014). There are also 
some differences in findings. For example, Shyu \& Huang (2011) states that there is no PEoU effect on AtU.

In this study, the AtU attribute is to measure acceptance or rejection of students towards ECMS. The researcher expects AtU to influence student BI to use ECMS. Therefore, the hypothesis 9 is proposed.

H9: There is a positive and direct impact of AtU towards the BI of ECMS.

\section{Behavioural Intention (BI)}

BI is a behavioral tendency to continue use a technology in the future. Many studies have investigated BI on technology acceptance and the findings show that BI has a positive relationship with AU (Tarhini et al., 2014; Shyu \& Huang, 2011).

There are several factors that influence BI in studies focusing on online learning including PU (Wu et al., 2013; Tarhini et al., 2014; Shyu \& Huang, 2011), PEoU (Wu et al., 2013; Tarhini et al., 2014), social norms (Tarhini et al., 2014) and quality of work culture (Tarhini et al., 2014).

In this study, researchers study the BI attributes of actual use. Researchers expect students to continue using ECMS in the future. Therefore, the hypothesis 10 is proposed.

H10: There is positive and direct impact of BI towards the AU of ECMS.

Actual Use (AU)

The AU is the obvious condition of the use of a technology. It is measured by the frequency and duration of the use of the technology. Straub et al., (1995) found that the $\mathrm{AU}$ of the system has significant practical value to assess the impact of information technology. Igbaria et al., (1995) define AU as the amount of time interacting with technology and frequency of use. In this study, researchers measure AU students through the time allocated by students to use ECMS.

\section{METHOD}

In this study, a total of 42 students from the School of Industrial Technology, Universiti Sains Malaysia (USM) enrolled for IMK 209: Food Physical Properties course was involved in this study. These students were using ECMS in this course. After 12 weeks using the ECMS, a survey was conducted. The survey data were obtained by means of a questionnaire containing of 28 items grouped under 7 constructs based on TAM as presented in Table 1. The data were collected using a five-point Likert Scale $(5=$ strongly agree, $4=$ agree, $3=$ average, $2=$ disagree, $1=$ strongly disagree) for each item. The Cronbach's alpha was calculated to be .939 . This indicates that all the items in the test exhibit high reliability and measure the same concept. The internal reliabilities of multi-item constructs given in the last column of Table 1 also exhibit adequate reliability. For establishing content validity, the items and their corresponding constructs were adapted from prior studies and modified according to the context of the present study. 
Table 1

Cronbach Alpha Coefficient Value

\begin{tabular}{lll}
\hline Attributes & Number of items & Alpha \\
\hline Motivation (Mo) & 3 & 0.834 \\
Content Quality (CQ) & 8 & 0.776 \\
Perceived Usefulness (PU) & 5 & 0.783 \\
Perceived Ease of Use (PEoU) & 4 & 0.880 \\
Attitude towards Use (AtU) & 3 & 0.741 \\
Behavioural Intention (BI) & 2 & 0.763 \\
Actual Use (Au) & 3 & 0.824 \\
\hline Total & 28 & 0.939 \\
\hline
\end{tabular}

\section{FINDINGS}

\section{Correlation Analysis}

Table 2 shows the correlation matrix between the attributes studied. The findings show that the correlation between all attributes is significant $(\mathrm{p}<0.05)$ and positive except the correlation between CQ $\rightarrow$ AU. The findings also show that the majority of coefficient of correlation ( $r$ ) is greater than 0.5 which means the relationship between the two variables is very strong. Among all the attributes, it is found that PU $\rightarrow$ PEoU shows a high $r$ value of $0.786(p<0.01)$ while the $r$ value of $C Q \rightarrow A U$ is the lowest of 0.295 . It shows the relationship between the two attributes is very weak.

Table 2

The Correlation Matrix between the TAM Attributes

\begin{tabular}{llllllll}
\hline Attribute & Mo & CQ & PU & PEoU & AtU & BI & AU \\
\hline Mo & 1.000 & & & & & & \\
CQ & $0.415^{* *}$ & 1.000 & & & & & \\
PU & $0.589^{* *}$ & $0.630^{* *}$ & 1.000 & & & & \\
PEoU & $0.581^{* *}$ & $0.543^{* *}$ & $0.786^{* *}$ & 1.000 & & & \\
AtU & $0.491^{* *}$ & $0.412^{* *}$ & $0.662^{* *}$ & $0.662^{* *}$ & 1.000 & & \\
BI & $0.583^{* *}$ & $0.514^{* *}$ & $0.701^{* *}$ & $0.699^{* *}$ & $0.605^{* *}$ & 1.000 & \\
AU & $0.355^{*}$ & 0.295 & $0.480^{* *}$ & $0.542^{* *}$ & $0.448^{* *}$ & $0.571^{* *}$ & 1.000 \\
\hline
\end{tabular}

** The correlation was significant at 0.01 (2-tailed)

\section{Multiple Regression}

Table 3 shows the hypothesis testing of the structure model. The findings show that among the three independent variables, the PEoU attribute is the largest contributor to PU's dependent variable (PEoU $\rightarrow \mathrm{PU} ; \beta=0.548$ ). While independent variables, Mo attributes are the largest contributors to the dependent variable PEoU $(\mathrm{Mo} \rightarrow \mathrm{PEoU} ; \beta=$ 0.429). Among the independent variables, PU attributes and PEoU attributes, it was found that PEoU attributes were the main contributors to the dependent variable of AtU $(\mathrm{PEoU} \rightarrow \mathrm{AtU} ; \beta=0.925)$. On the other hand, the PU attribute is the largest contributor to the $\mathrm{BI}$ dependent variable $(\mathrm{PU} \rightarrow \mathrm{BI} ; \beta=0.536)$. 
Table 3

Multiple Regression Analysis of MPT Attributes

\begin{tabular}{lllllll}
\hline DV & $\mathrm{R}^{2}$ & IV & Beta $(\beta)$ & Standard Error of $\beta$ & t-statistic & Significance \\
\hline PU & 0.693 & Mo & 0.161 & 0.102 & 1.443 & $p>0.05$ \\
& & CQ & 0.265 & 0.160 & 2.451 & $p<0.05$ \\
& & PEoU & 0.548 & 0.089 & 4.530 & $p<0.001$ \\
PEoU & 0.447 & Mo & 0.429 & 0.162 & 3.280 & $p<0.05$ \\
& & CQ & 0.365 & 0.262 & 2.789 & $p<0.05$ \\
AtU & 0.766 & PU & -0.065 & 0.150 & -0.518 & $p>0.05$ \\
& & PEoU & 0.925 & 0.110 & 7.396 & $p<0.001$ \\
BI & 0.527 & PU & 0.536 & 0.195 & 3.646 & $p<0.05$ \\
& & AtU & 0.250 & 0.163 & 1.699 & $p>0.05$ \\
AU & 0.326 & BI & 0.571 & 0.095 & 4.394 & $p<0.001$ \\
\hline
\end{tabular}

Figure 2 shows the results of the hypothesis model. For PU, the findings show the attributes of CQ (H3: CQ $\rightarrow$ PU; $\beta=0.265, p<0.05)$ and PEoU attributes (H5: PEoU $\rightarrow \mathrm{PU} ; \beta=0.548, \mathrm{p}<0.001) \mathrm{H} 1:$ Mo $\rightarrow \mathrm{PU} ; \beta=0.161, \mathrm{p}>0.05)$ did not significantly affected the PU. These three attributes show $69.3 \%$ variance in PU.

The Mo attributes $(\mathrm{H} 2: \mathrm{Mo} \rightarrow \mathrm{PEoU} ; \beta=0.429, \mathrm{p}<0.05)$ and CQ attributes (H4: CQ $\rightarrow$ PEoU; $\beta=0.365, p<0.05$ ) in PEoU. Meanwhile, the PEoU attributes (H6: PEoU $\rightarrow$ AtU; $\beta=0.925, p<0.001$ ) have significantly affected AtU positively but differently with PU (H7: PU $\rightarrow$ AtU; $\beta=-0.065, p>0.05$ ) have a significant impact and negative with AtU. The findings show that both attributes account for $76.6 \%$ of the variance in AtU.

$\mathrm{PU}(\mathrm{H} 8: \mathrm{PU} \rightarrow \mathrm{BI} ; \beta=0.536, \mathrm{p}<0.05)$ showed significant positive relationship with $\mathrm{BI}$ while AtU attributes (H9: AtU $\rightarrow \mathrm{BI} ; \beta=0.250, \mathrm{p}<0.05$ ). These two attributes explain $52.7 \%$ of the variances in the BI. While the BI attribute $(\mathrm{H} 10: \mathrm{BI} \rightarrow \mathrm{AU} ; \beta=0.571, \mathrm{p}$ $<0.001)$ significantly affected PS with positive effect by contributing $32.6 \%$ variance in AU.

Table 4 shows the overall analysis of the TAM attributes.

Table 4

Results of Hypothesis

\begin{tabular}{lllll}
\hline Hypothesis & Effects & Direction & $\begin{array}{l}\text { Path } \\
\text { Coefficient }\end{array}$ & $\begin{array}{l}\text { Result } \\
\text { (Support to Hypotheses) }\end{array}$ \\
\hline $\mathrm{H}_{1}$ & $\mathrm{Mo} \rightarrow$ PU & Positive & 0.161 & Not Supported \\
$\mathrm{H}_{2}$ & $\mathrm{Mo} \rightarrow \mathrm{PEoU}$ & Positive & 0.429 & Supported \\
$\mathrm{H}_{3}$ & $\mathrm{CQ} \rightarrow \mathrm{PU}$ & Positive & 0.265 & Supported \\
$\mathrm{H}_{4}$ & $\mathrm{CQ} \rightarrow \mathrm{PEoU}$ & Positive & 0.365 & Supported \\
$\mathrm{H}_{5}$ & $\mathrm{PEoU} \rightarrow \mathrm{PU}$ & Positive & 0.548 & Supported \\
$\mathrm{H}_{6}$ & $\mathrm{PEoU} \rightarrow \mathrm{AtU}$ & Positive & 0.925 & Supported \\
$\mathrm{H}_{7}$ & $\mathrm{PU} \rightarrow \mathrm{AtU}$ & Negative & -0.065 & Not Supported \\
$\mathrm{H}_{8}$ & $\mathrm{PU} \rightarrow \mathrm{BI}$ & Positive & 0.536 & Supported \\
$\mathrm{H}_{9}$ & $\mathrm{AtU} \rightarrow \mathrm{BI}$ & Positive & 0.250 & Not Supported \\
$\mathrm{H}_{10}$ & $\mathrm{BI} \rightarrow \mathrm{AU}$ & Positive & 0.571 & Supported \\
\hline
\end{tabular}




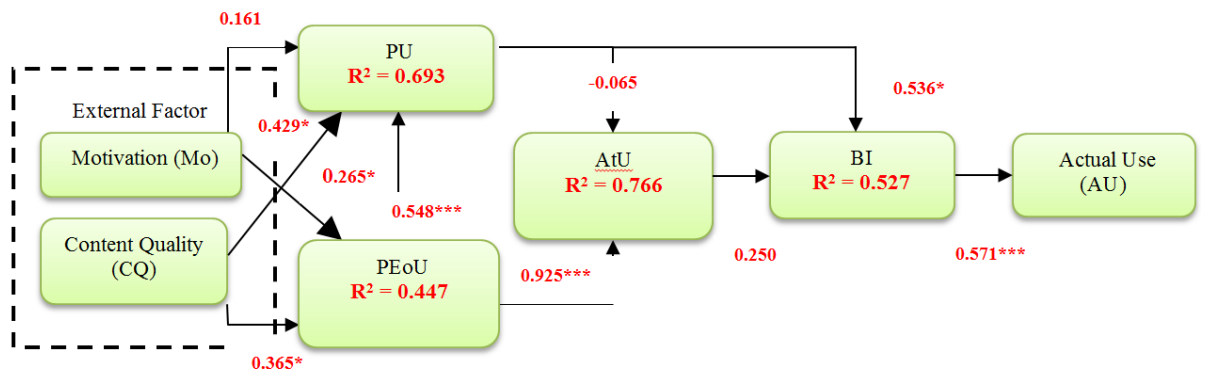

Figure 2

Testing the Hypotheses of the Structural Model

\section{DISCUSSION AND CONCLUSION}

The main purpose of this study is to examine the relationship between the attributes of the Technology Acceptance Model that influence the student's behavioral intention to use ECMS. BI is one of the important factors in determining the AU of ECMS. The success of such a system is measured through the involvement of students in using the system. Therefore, it is important to evaluate student acceptance to ensure that at the end of the learning, students adopt this learning platform in their learning.

One of the interesting results of the study is that the external variable, content quality, plays an important role in directly affecting perceived usefulness and perceived ease of use toward ECMS. This finding is supported by studies conducted by Hong et al., (2001) and Pituch \& Lee (2006) who found that CQ is an important external factor affecting PEoU and PU. According to Pituch \& Lee (2006), the function of system that refers to content quality affects the PU and PEoU positively. A technology will affect the PEoU if the time response is faster and the ease of access to content is efficient (Pituch \& Lee, 2006). Zhang et al., (2000) proved that high CQ influenced perceptions of feasibility and perception of assessment. However, there are different findings. Wu et al., (2008) found that CQ did not significantly affect PEoU but significantly influenced the perception of the assessment. As students are familiar with technology tools, the usability and tools of the technology are not an obstacle for them.

The findings of this study support the hypothesis 3 and hypothesis 4 because CQ offers useful information with appropriate online features and content design that satisfies students. Additionally, content designs that use audio, video and texts make it easier for students to follow learning materials while affecting ECMS's usability. Therefore, researchers conclude that the relevant CQ and the use of various types of media and activities such as training, quizzes and illustrations can enhance the usability and use of ECMS.

In terms of perceived usefulness, the findings confirm those of other studies (Khor, 2014) indicating that perceived usefulness to be among the strongest of the determinants from the TAM model. Hence, students who think the system is useful in their education are more likely to adopt the system. Therefore, lecturer and developers of e-learning need to improve the content quality of their e-learning systems in order to encourage 
students to use them more extensively. One interesting observation is that, in assessing the proposed model, attitude towards use demonstrated a weak direct effect on behavioural intention. This finding is in line with Sun (2003) and Taylor and Todd (1995) reporting that attitude towards use does not significantly affect behavioural intention. A study conducted by Sun (2003) found that AtU was not a factor that could affect the BI. Taylor and Todd (1995) also found that AtU is not an important determinant to $\mathrm{BI}$ although the relationship between AtU and BI is more important to experienced users. Chau and $\mathrm{Hu}$ (2001) shows that users are likely to have a positive AtU if they believe that the use of technology is capable of improving their performance and productivity. Venkatesh and Davis (2000) found that AtU was a weak predictor for $\mathrm{BI}$ or AU. His studies show that BI and AU affect PU and PEoU but do not affect AtU through BI.

This study does not support Hypothesis 9 because students have no previous experience with ECMS. Student AtU may be enhanced by providing knowledge and experience using ECMS. This disclosure attempts to increase their confidence while changing the AtU against ECMS. This research has presented data showing the level of student satisfaction with ECMS as an additional tool in supporting teaching and learning. ECMS seeks to encourage collaborative, constructive and generative learning. This studentcentered learning approach is able to enhance students' understanding, improve student's self-esteem and motivation, and the enhancement of student's knowledge construction.

\section{IMPLICATION}

The first implication obtained from this research is the satisfaction of students towards ECMS influenced by BI, AtU, PU, Mo and CQ. Two important attributes in the TAM, namely PU and PEoU of a system show a positive relationship to ECMS. Students find that ECMS is very easy to use and useful to them while affecting the actual use of students. Therefore, this research helps to identify factors that influence student acceptance of a technology.

In addition, external factors such as motivation and content quality are also found to influence the perceptions of usability and perceptions of ease of use. The second implication is that this research can help stakeholders in e-learning especially administration, lecturer, learning designers, content specialists and educational technologist to better understand the attributes of technology acceptance, collaborative effectiveness, the advantage of using ECMS as well as the importance of interaction between students and students-lecturers. The third implication that can be derived from this study is that the findings provide an insight on how lecturers may enhance the effectiveness of the learning process using web-based learning environment and flipped learning. Through the use of ECMS, the collaborative approach is able to develop student's social skills, communication skills, leadership, teamwork and problem-solving skills.

\section{REFERENCES}

Abduljalil, K. M., \& Zainuddin, Y. (2015). Integrating technology acceptance model and motivational model towards intention to adopt accounting information system. International Journal of Management, Accounting and Economics, 2(5), 346-359. 
Abdullah, F., \& Ward, R. (2016). Developing a general extended technology acceptance model for e-learning (GETAMEL) by analysing commonly used external factors. Computers in Human Behavior, 56, 238-256. http://dx.doi.org/10.1016/j.chb.2015.11.036.

Alharbi, S., \& Drew, S. (2014). Using the technology acceptance model in understanding academics' behavioural intention to use learning management systems. International Journal of Advanced Computer Science and Applications, 5(1), 143-155.

Al-Assaf, N., Almarabeh, T., \& Eddin, L. (2015) a study on the impact of learning management system on students of the university of Jordan. Journal of Software Engineering and Applications, 8, 590-601. http://dx.doi.org/10.4236/jsea.2015.811056.

Anormaliza, R., Ivan, R., Sabaté i Garriga, F., \& Guevara Viejo, F. (2015). Evaluating student acceptance level of e-learning systems, In ICERI2015: Proceedings 8th International Conference of Education, Research and Innovation (pp. 2393-2399). Seville, Spain.

Barker, P. (1994). Designing interactive learning. In T. de Jong, \& L. Sarti (Eds). Design and production of multimedia and simulation-based learning material (pp. 130). Dordrech: Kluwer Academic Publishers.

Bergmann, J., \& Sams, A. (2012). Flip your classroom: Reach every student in every class every day. Washington DC: International Society for Technology in Education.

Bruce K. G. (2013, April). Integrating Edmodo into a high school service club: To promote interactive online communication. Paper presented at 18th Annual TCC online conference 2013, Hawai, USA.

Calisir, F., Gumussoy, C. A., Bayraktaroglu, A. E., \& Karaali, D. (2015). Predicting the intention to use a web-based learning system: perceived content quality, anxiety, perceived system quality, image, and the technology acceptance model. Human Factors and Ergonomics in Manufacturing \& Service Industries, 24(5), 515-531.

Chau, P., \& Hu, P. (2001). Information technology acceptance by individual professionals: a model comparison approach. Decision Sciences, 32(4), 699-719.

Chen, H., \& Tseng, H. (2012). Factors that influence acceptance of web-based elearning systems for the in-service education of junior high school teachers in Taiwan. Evaluation and Program Planning, 35(3), 398-406.

Cheng, Y. (2012). Effects of quality antecedents on e-learning acceptance. Internet Research, 22(3), 361-390.

Cheng, Y. (2013). Nurse education today exploring the roles of interaction and flow in explaining nurses' e-learning acceptance. YNEDT, 33(1), 73-80.

Cheung, R., \& Vogel, D. (2013). Computers \& education predicting user acceptance of collaborative technologies: An extension of the technology acceptance model for elearning. Computers \& Education, 63, 160-175.

Davis, F. D. (1986). A technology acceptance model for empirically testing new enduser information systems: Theory and results (Unpublished doctoral dissertation). MIT Sloan School of Management, Cambridge, MA. 
Davis, F. D. (1989). Perceived usefulness, perceived ease of use and user acceptance of information technology. MIS Quarterly, 13, 319-339.

Deci, E. L., \& Ryan, R. M. (1975). Intrinsic motivation. New York: Plenum Press.

Deci, E., \& Ryan, R. (1985). Intrinsic motivation and self-determinaton in human behaviour. New York: Plenum.

Dogan, B. (2012). Educational uses of digital storytelling in K-12: Research results of digital story-telling contest (DISTCO) 2012. In P. Resta (Eds), Proceedings of Society for Information Technology \& Teacher Education International Conference 2012 (pp. 1353-1362). Austin, Texas.

Esterhuyse, M., \& Scholtz, B. (2016). The intention to use e-learning in corporations. In Proceedings of the 2nd International Conference on Information Resources Management (pp. 3-18). Cape Town, South Africa.

Haderi, S. M. A. (2014). System characteristic facilities the acceptance of information technology in middle east culture. International Journal of Business and Social Science, 5(6-1), 64-69.

Healey, K. \& Brayn-Kinns, B. (2000). Analyzing asynchronous collaboration. Proceeding of the HCI 2000.

Hediyeh M., Alireza H., \& Davood K. M. (2013). Factors affecting university instructors' adoption of web-based learning systems: case study of Iran. Computers \& Education, 61, 158-167.

Hong, W., Thong, J., Wong, W., \& Tam, K. (2001). Determinants of user acceptance of digital libraries: An empirical examination of individual differences and system characteristics. Journal of Management Information Systems, 18(3), 97-124.

Hsu, H. H., \& Chang, Y. Y. (2013). Extended TAM model: Impacts of convenience on acceptance and use of moodle. US-China Education Review, 3(4), 211-218.

Huang, C. (2017). Cognitive factors in predicting continued use of information system with technology adoption model. Published Quarterly by the University of Boras, Sweden, 22(2).

Igbaria, M., Livari, J., \& Maragahh, H. (1995). Why do individuals use computer technology? A Finnish case study. Information \& Management, 29, 227-238.

Jung, Y., Perez, Mira, B., \& Wiley Patton, S. (2009). Consumer adoption of mobile TV: Examining psychological flow and media content. Computers in Human Behavior, 25(1), 123-129. https://doi.org/10.1016\%2Fj.chb.2008.07.011.

Khor, E. T. (2014). Collaborative content organiser (CCO) learning system: an empirical study using the technology acceptance model (TAM) (Unpublisehd doctoral dissertation) Universiti Sains, Malaysia.

Kongchan, C. (2013, May). How Edmodo and Google Docs can change traditional classrooms. Paper presented at The European Conference on Language Learning 2013, Brighton, United Kingdom. 
Lai, C., Wang, Q., \& Lei, J. (2012). What factors predict undergraduate students' use of technology for learning? A case from Hong Kong. Computers \& Education, 59(2), 569-579. https://doi.org/10.1016/j.compedu.2012.03.006.

Lee, D. Y., \& Lehto, M. R. (2013). User acceptance of YouTube for procedural learning: An extension of the technology acceptance model. Computers \& Education, 61, 193-208. https://doi.org/10.1016/j.compedu.2012.10.001.

Lee, M. K. O., Cheung, C. M. K., \& Chen, Z. (2005). Acceptance of internet-based learning medium: The role of extrinsic and intrinsic motivation. Information \& Management, 42, 1095-1104.

Lee, Y. C. (2006) An empirical investigation into factors influencing the adoption of an e-learning system. Online Information Review, 30, 517-541.

Lee, Y., Hsieh, Y., \& Chen, Y. (2013). An investigation of employees' use of e-learning systems: Applying the technology acceptance model. Behaviour and Information Technology, 32, 173-189. https://doi.org/10.1080/0144929X.2011.577190.

Lee, Y., Hsiao, C., \& Purnomo, S. H. (2014). An empirical examination of individual and system characteristics on enhancing e-learning acceptance. Australasian Journal of Educational Technology,30(5), 562-579. https://doi.org/10.14742/ajet.381.

Legris, P., Ingham, J., \& Collerette, P. (2003). Why do people use information technology? A critical review of the technology acceptance model. Information \& Management,40(3), 191-204. https://doi.org/10.1016/s0378-7206(01)00143-4.

Lin, K. Y., \& Lu, H. P. (2011). Why people use social networking sites: An empirical study integrating network externalities and motivation theory. Computers in Human Behavior, 27(3), 1152-1161.

Lin, S. C., Persada, S. F., \& Nadlifatin, R. (2014). A study of student behavior in accepting the blackboard learning system: A technology acceptance model (TAM) approach. In 2014 IEEE 18th International Conference on Computer Supported Cooperative Work in Design (CSCWD) (pp. 457-462). Taiwan: National Tsing Hua University.

Masa'deh, R., Tayeh, M., Al-Jarrah, I. M., \& Tarhini, A. (2015). Accounting vs. market-based measures of firm performance related to information technology investments. International Review of Social Sciences and Humanities, 9(1), 129-145.

Moon, J. W., \& Kim, Y. G. (2001), Extending TAM for a world-wide-web context. Information and Management, 38, 217-230.

Moore, G. C., \& Benbasat, I. (1991). Development of an instrument to measure the perceptions of adopting an information technology innovation. Information Systems Research, 2, 192-222.

Nagy, J. T. (2018). Evaluation of online video usage and learning satisfaction: an extension of the technology acceptance model, International Review of Research in Open and Distributed Learning, 19(1), 160-185.

Park, Y., Son, H., \& Kim, C. (2012). Automation in construction investigating the determinants of construction professionals' acceptance of web-based training: An 
extension of the technology acceptance model. Automation in Construction, 22, 377386.

Pituch, K. A., \& Lee, Y. K. (2006). The influence of system characteristics on elearning use. Computers \& Education, 47(2), 222-244.

Purnomo, S. H., \& Lee, Y. (2013). E-learning adoption in the banking workplace in Indonesia: an empirical study. Information Development, 29(2), 138-153.

Saade, R. G. (2007). Dimensions of perceived usefulness: Toward enhanced assessment. Decision Sciences Journal of Innovative Education, 5(2), 289-310.

Saadé, R., \& Bahli, B. (2005). The impact of cognitive absorption on perceived usefulness and perceived ease of use in on-line learning: An extension of the technology acceptance model. Information and Management, 42, 317-327.

Shyu, S. H., \& Huang, J. (2011). Elucidating usage of e-government learning: A perspective of the extended technology acceptance model. Government Information Quarterly, 28(4), 491-502. http://doi.org/10.1016/j.giq.2011.04.002.

Sik, Y., \& Lee, H. (2010). Computers in human behavior understanding the role of an IT artifact in online service continuance: An extended perspective of user satisfaction. Computers in Human Behavior, 26(3), 353-364.

Straub, D., Limayem, M., \& Karahanna-Evaristo, E. (1995) Measuring system usage: Implications for IS theory testing. Management Science, 41(8), 1328-1342.

Sun, H. (2003, August). Toward a deeper understanding of technology acceptance model: An integrative analysis of TAM. Paper presented at Americas Conference on Information Systems (AMCIS 03), Tampa, Florida.

Taherdoost, H., Jalaliyoon, N., Namayandeh, M., Forghani, A., \& Zamani, M. (2011). Adoption framework expansion based on the computer ethics' related research models and ethical scenarios analysis, In Proceedings of the 2010 International Conference on Economics, Business and Management (IPEDR) (pp. 219-223). Manila, Philippines: IACS IT Press.

Tan, W. (2010). E-learning systems adoption across cultures : A comparison study. EProduct E-Service and E-Entertainment (ICEEE), 2010 International Conference on Henan, 1-4.

Tarhini, A., Hone, K., \& Liu, X. (2013). Factors affecting students' acceptance of elearning environments in developing countries: A structural equation model approach. International Journal of Information and Education Technology, 3(1), 54-59.

Tarhini, A., Hone, K., \& Liu, X. (2014). The effects of individual differences on elearning users' behaviour in developing countries: A structural equation model. Computers in Human Behavior, 41, 153-163.

Tarhini, A., Elyas, T., Akour, M.A \& Al-Salti, Z. (2016). Technology, demographic characteristics and e-learning acceptance: A conceptual model based on extended technology acceptance model. Higher Education Studies, 6(3), 72-89.

Taylor, S., \& Todd, P. A. (1995). Understanding information technology usage: A test of competing models. Information Systems Research, 6(2), 144-176. 
Taylor, P., Wu, B., \& Zhang, C. (2014). Empirical study on continuance intentions towards E- Learning 2.0 systems. Behaviour \& Information Technology, 33(10), 1027-1038. Thongmak, M. (2013). Social network system in classroom: Antecedents of Edmodo $\odot$ Adoption. Journal of e-Learning and Higher Education, 2013, 1-15. http://dx.doi.org/10.5171/2013.657749.

Teo, T. (2014): Modelling Facebook usage among university students in Thailand: the role of emotional attachment in an extended technology acceptance model. Interactive Learning Environments, 24(6), 747-757. https://doi.org/10.1080/10494820.2014.917110.

Tucker, B. (2012). The flipped classroom. Education Next, 12(1), 82. Retrieved from http://educationnext.org/ the-flipped-classroom/.

Udo, G. J., Bagchi, K. K., \& Kirs, P. J. (2010). An assessment of customers' e-service quality perception, satisfaction and intention. International Journal of Information Management, 30(6), 481-492. https://doi.org/10.1016/j.ijinfomgt.2010.03.005.

Venkatesh, V., \& Davis, F. D. (2000). A theoretical extension of the technology acceptance model: four longitudinal field studies. Management Science, 46(2), 186-204. https://doi.org/10.1287/mnsc.46.2.186.11926.

Teeroovengadum, V., Heeraman, N., \& Jugurnath, B., (2017). Examining the antecedents of ICT adoption in education using an extended technology acceptance model (TAM). International Journal of Education and Development using Information and Communication Technology (IJEDICT), 13(3), 4-23.

Wu, B., \& Zhang, C. (2014). Empirical study on continuance intentions towards ELearning 2.0 systems. Behaviour \& Information Technology, 33(10), 1027-1038, http://dx.doi.org/10.1080/0144929X.2014.934291.

Wu, M., Chou, H., Weng, Y., \& Huang, Y. (2008). A study of Web 2.0 Website usage behaviour using TAM 2. In Asia-Pacific Services Computing Conference, 2008. APSCC'08. IEEE (1477-1482).

Wu, C., Kuo, Y., \& Wu, S. (2013). Investigating the antecedents of university students' behavioral intention to use ipad for learning. International Journal of e-Education, $e$ Business, e-Management and e-Learning, 3(6), 468-471.

Yeou, M. (2016). An investigation of students' acceptance of Moodle in a blended learning setting using technology acceptance model. Journal of Educational Technology Systems,44(3), 300-318. http://dx.doi.org/10.1177/0047239515618464

Young, D., \& Lehto, M. R. (2013). User acceptance of YouTube for procedural learning: An extension of the Technology Acceptance Model. Computers \& Education, 61, 193-208. https://doi.org/10.1016/j.compedu.2012.10.001.

Yucel, U. A. (2013). Technology acceptance model: A review of the prior predictors. Ankara University, Journal of Faculty of Educational Science, 46(1), 89-109.

Zhang, P., Von Dran, G., Blake, P., \& Pipithsuksunt, V. (2000). A comparison of the most important website features in different domains: an empirical study of user perceptions. Proceeding of the $6^{\text {th }}$ Americas Conference on Information System (pp. 1367-1372). Long Beach, CA. 